\title{
Neurourology in spinal cord injured patients
}

\author{
J J Wyndaele MD \\ Centre for Urodynamics and Urological Re-education, University Hospital, Ghent, \\ Belgium.
}

It is largely because of detailed attention to the urinary tract that the life expectancy of spinal cord injured (SCI) patients has been increased and their quality of life improved. ${ }^{1}$ A growing understanding of what is happening in the lower urinary tract in general and in spinal man in particular has made the management of bladder dysfunction in these patients more accurate. As a direct consequence of this, some urinary complications have become less frequent, and others less life threatening. One should be aware however that this situation resulted mainly from the application of very high standards of comprehensive treatment and from an intensive long term follow-up. If one looks back in history it is important to realise that an early death after spinal cord injury from urinary sepsis was still practically inevitable, even less than 100 years ago. ${ }^{2,3}$ A continuous effort will have to be made to keep up the high standards of treatment that we actually practice and this against economic, social and community related countercurrents.

Urological treatment starts in the acute post injury period. An accurate and comprehensive neurological assessment in the accident department is fundamental to the early diagnosis of bladder dysfunction in spinal injury. In a patient with complete SCI spinal shock is characterised by paralysis of the detrusor muscle and consequent urinary retention. The duration of this period can vary from a few weeks to several months during which bladder drainage is needed. Complications of indwelling catheters are so difficult to manage that every effort should be directed to avoid them. Intermittent catheterisation has proved to be the method of choice. It leaves the bladder without foreign material, provides for regular complete emptying and results in very few complications if properly performed. ${ }^{4-6}$ Early self catheterisation may help to overcome a nursing staff shortage in a busy acute SCI ward without influencing the final outcome of bladder training. ${ }^{7}$

As soon as patients recover from spinal shock, a detailed evaluation of the lower urinary tract function has to be done. The choice of method for bladder emptying can be deduced from pressure-volume relationships during bladder filling and micturition as documented by urodynamic tests. ${ }^{8}$ Clinical neurological examination still continues to be helpful in the urological management of SCI patients and especially in units without the necessary urodynamic equipment. In at least $80 \%$ of patients clinical examination can provide valuable basic information concerning the type of neuropathic bladder, the completeness of the lesion and the activity of the external urethral sphincter: data which can help to guide the initial management. ${ }^{9}$ But there is no accurate clinical method available to determine if the bladder pressure is low enough. Periodic cystometrograms should therefore be done if possible during the acute period as well as during the re-education process. ${ }^{10,11}$ Simple uroflowmetry is neither a technique which is practical to perform on SCI patients, nor does it yield much useful information because the neuropathic bladder will not empty precisely to order. The use of extensive urodynamic equipment combined with radioscopy or ultrasound may permit a complete evaluation in specific cases. ${ }^{12}$ For routine evaluations an experienced investigator can gather a wealth of information with a one or two channel cystometer and with EMG of the urethral sphincter. ${ }^{13}$ The use of electrodiagnostic tests can improve the neurological diagnosis ${ }^{14,15}$ The early investigation of 
bladder electrosensation and the measurement of the conductance time of an electrical stimulus in the lumbosacral reflexes often permit an early choice of treatment in patients with lower spinal cord lesions.

Classical tests like the Bethanechol supersensitivity test ${ }^{16}$ and the ice-water test ${ }^{17}$ can still be of clinical use, but the investigator must be aware that false positive and false negative results may exist. ${ }^{18}$

Different neurourological classifications have been proposed in spinal men, starting from the upper motor neuron/lower motor neuron differentiation ${ }^{19}$ to more detailed, urodynamically oriented schemes providing an objective description of all aspects of the neuropathic voiding dysfunction. ${ }^{20} \mathrm{~A}$ very complete functional classification combining several urodynamic data has been proposed recently by Staskin and Krane. ${ }^{13}$

Many therapeutic possibilities exist to obtain a balanced bladder function. The overriding principles of the urological reeducation still are preservation of renal function, catheter freedom, avoidance of infection and urinary continence. When defining a new method of bladder management, a multitude of additional considerations may influence the final decision, apart from the urodynamic data: age, sex, level of SCI, extent of the lesion, social and economic conditions, the degree of ambulation and of independence. A main goal is the achievement of as complete as possible bladder emptying with low pressure. Suprapubic tapping and the Crédé manoeuvre and/or straining continue to be the basic retraining methods in SCI patients with a chronic neuropathic bladder. The best way to perform these techniques has to be ascertained for each individual patient. What is an acceptable amount of residual urine is still debatable. A low residual urine however does not mean that micturition or filling are achieved in a urodynamically safe way. This once more shows the importance of urodynamic investigations in the evaluation of the therapeutic outcome.

Intermittent self catheterisation has become very popular and good clinical results have been reported. ${ }^{21}$ However an increasing number of urethral complications has been found in male patients who self cathe- terise for more than 5 years. ${ }^{22}$ It will become possible to evaluate the long term effects of catheterisation (after 15-20 years) in a large number of patients in the near future. This will permit a detailed study of the long term complications and the way to prevent them.

Pharmacotherapy has become an important part of urological treatment in SCI patients. Neuropharmacological drugs may be very valuable in improving the clinical results of re-education and catheterisation. ${ }^{23,24}$

To reduce urethral resistance transurethral sphincterotomy and bladder neck surgery have been used for many years. Balloon dilatation and stenting the sphincter in an open attitude have been done recently with some satisfactory results in a limited number of patients, ${ }^{25,26}$ but long term assessment is still awaited.

Urinary tract infection remains the most frequent urological complication. ${ }^{27}$ The aim should be to prevent rather than treat infection and its complications. ${ }^{28}$ It is however imprudent to attempt prevention of colonisation of the urinary tract in SCI patients by chronic suppression of pathogenic organisms. Ensuring the general well being of the patient, adequate drainage of the urinary tract and preservation of a healthy bacterial commensal environment seem to be of the upmost importance in infection prevention. Antimicrobial therapy should be reserved for accurate and effective use during episodes of significant clinical infection. ${ }^{29}$ Today we have very potent antibiotics at our disposal. That these are only used when there are clear indications is a heavy responsibility shared by all of those in charge. Therapy by powerful antibiotics without accurate screening should be emphatically discouraged.

In a SCI patient life long follow-up is needed. As this depends on the active participation of many, educating the patients themselves, their families, nurses and physicians in the community must be an integral part of the rehabilitation programme. Though it is well accepted that the management of SCI patients is best done by those with special experience in the field, many patients are still managed in centres 
that are not specialised. It would seem essential therefore to try to ensure that urologists who treat these patients are well informed.

The frequency and nature of review after discharge from hospital will depend on the state in which the urinary tract has been stabilised in the individual patient. Microbiological tests are vital. Chemotherapy or antibiotics should be prescribed promptly if appropriate. The intravenous urogram has for many years been the mainstay of the urological follow-up after SCI, and has been done in conjunction with biochemical tests every year or 2 years. Ultrasonography may be a less invasive alternative for routine follow-up investigation. Upper urinary tract dilatation should always be investigated and treatment instituted. ${ }^{30}$

Urological surgical treatment has seen great progress in the last few years: urinary stone treatment with extracorporial shock wave therapy, percutaneous litholapaxy, bladder augmentation procedures, etc. Recent urological innovations include the use of electronic means to control voiding and continence. ${ }^{31,32}$

All involved with SCI patients have great hopes that nerve regeneration and grafting to reduce the neurological deficit might in future become clinically applicable in man. Intensive work is being done by several investigators throughout the world and their progress is being followed with keen interest. Until the day that these acts of curing the patient become possible, it remains the mission of all providers for the urological care of SCI patients to continue to improve the management of this most hazardous dysfunction in spinal man.

\section{References}

1 Geisler WO, Jousse AT, Wynne-Jones M, Breithaupt D (1983) Survival in traumatic spinal cord injury. Paraplegia 21: 364-373.

2 Besley FA (1917) A plea for the non catheterisation of the urinary bladder in cases of gunshot wounds of the spinal column. J Am Med Ass 69: 638-639.

3 Vellacott PN (1919) Spinal injury with retention of urine. The avoidance of catheterisation. Lancet 733-737.

4 Guttmann L, Frankel H (1966) The value of intermittent catheterisation in the early management of traumatic paraplegia and tetraplegia. Paraplegia 4: 63-83.

5 Ott R, Rossier AB (1972) L'intérêt du sondage intermittent dans la rééducation vésicale des lésions médullaires traumatiques aiguës. Urol Intern 27: 51-65.

6 O'Flynn JD (1974) Early management of neuropathic bladder in spinal cord injuries. Paraplegia 12: 83-86.

7 Wyndaele JJ, De Taeye RN (1990) Early intermittent self-catheterisation after spinal cord injury. Paraplegia 28: 76-80.

8 McGuire EF, Woodside JR, Barden TA, Wein R (1981) Prognostic value of urodynamic testing in myelodysplastic patients. J Urol 126: 205-209.

9 Wyndaele JJ (1984) A critical review of urodynamic investigations in spinal cord injury patients. Paraplegia 22: $138-144$

10 Rossier A, Fam B (1979) From intermittent catheterisation to catheter freedom via urodynamics: a tribute to Sir Ludwig Guttmann. Paraplegia 17: 73-85.

11 Gardner BP, Parsons KF, Jameson RM, Machin DG, Krishnan KR (1984) The role of urodynamics in the management of spinal cord injured patients. Paraplegia 22: 157-161.

12 Madersbacher H, Dietl P (1984) Urodynamic practice in neurourological patients : techniques and clinical value. Paraplegia 22: 145-156.

13 Staskin DR, Krane RJ (1991) A practical approach to urodynamic evaluation. In: Parsons KF, Fitzpatrick JM, eds. Practical Urology in Spinal Cord Injury. Springer Verlag, London: 11-26.

14 Glick M, Haldeman S, Meshkinpour H (1986) The neurovisceral and electrodiagnostic evaluation of patients with thoracic SCI. Paraplegia 24: 129-137.

15 Wyndaele JJ (1991) Investigation of the afferent nerves of the lower urinary tract in patients with 'complete' and 'incomplete' spinal cord injury. Paraplegia 29: 490-494.

16 Lapides J, Friend CR, Ajemian EP, Reus WG (1962) Denervation supersensitivity as a test for neurogenic bladder. Surg Gynec, Obstet 114: 241-244.

17 Bors E, Ma RT, Parker RB (1956) Observations on some modaliteis of bladder sensation. J Urol 76: $566-575$

18 Blaivas JG, Labib KB, Michalik SJ, Zayed AAH (1980) Failure of Bethanechol denervation supersensivity as a diagnostic aid. J Urol 123: 199-201.

19 Bors E, Comarr AE (1971) Neurological Urology. University Park Press, Baltimore: 129-135. 
20 Krane RJ, Siroky MB (1984) Classification of neuro urologic disorders. In: Barrett DM, Wein AJ, eds. Controversies in Neuro-Urology. Churchill-Livingstone, New York: 1984, 223-238.

21 Kuhn W, Rist M, Zach GA (1991) Intermittent urethral self-catheterisation: long term results (bacteriological evolution, continence, acceptance, complications). Paraplegia 29: 222-232.

22 Wyndaele JJ, Maes D (1990) Clean intermittent self-catheterisation: a 12-year follow-up. J Urol 143: 906-908.

23 Wyndaele JJ (1990) Review article. Pharmacotherapy for urinary bladder dysfunction in spinal cord injury patients. Paraplegia 28: 146-150.

24 Madersbacher H (1991) Control of detrusor hyperreflexia by the intravesical instillation of oxybutinin hydrochloride. Paraplegia 29: 84-90.

25 McInerney PP, Powell CS, Vanner TF, Stephenson TP (1990) Permanent urethral stents for detrusor sphincter dyssynergia. Presented at the 46th meeting of the British Association of Urological Surgery, Scarborough.

26 Shaw J, Timoney A, Barnes D (1991) Balloon dilatation of the external striated sphincter an alternative to external striated sphincterotomy. Presented at the 30th annual scientific meeting of the International Medical Society of Paraplegia, Stoke Mandeville Hospital, England.

27 Young JS (1982) Spinal Cord Injury Statistics: Experience of Regional Spinal Injury Systems. Good Samaritan Medical Centre, Phoenix: 34-35.

28 Wyndaele JJ (1987) Urology in spinal cord injured patients. Paraplegia 25: 267-269.

29 Ryan PC, Fitzpatrick JM (1991) Urinary tract infection. In: Parsons KF, Fitzpatrick JM, eds. Practical Urology in Spinal Cord Injury. Springer Verlag, London: 57-75.

30 Gardner BP, Parsons KF (1991) Upper urinary tract dilatation and stone. In: Parsons KF, Fitzpatrick JM, eds. Practical Urology in Spinal Cord Injury. Springer Verlag, London: 43-56.

31 Brindley GS, Polkey CE, Rushton DN, Cardozo L (1986) Sacral anterior root stimulation for bladder control in paraplegics - the first 50 cases. J Neurol Psychiatry 49: 1104-1114.

32 Tanagho EA, Schmidt RA (1988) Electrical stimulation in the clinical management of the neurogenic bladder. J Urol 140: 1331-1339. 